Provided for non-commercial research and education use. Not for reproduction, distribution or commercial use.

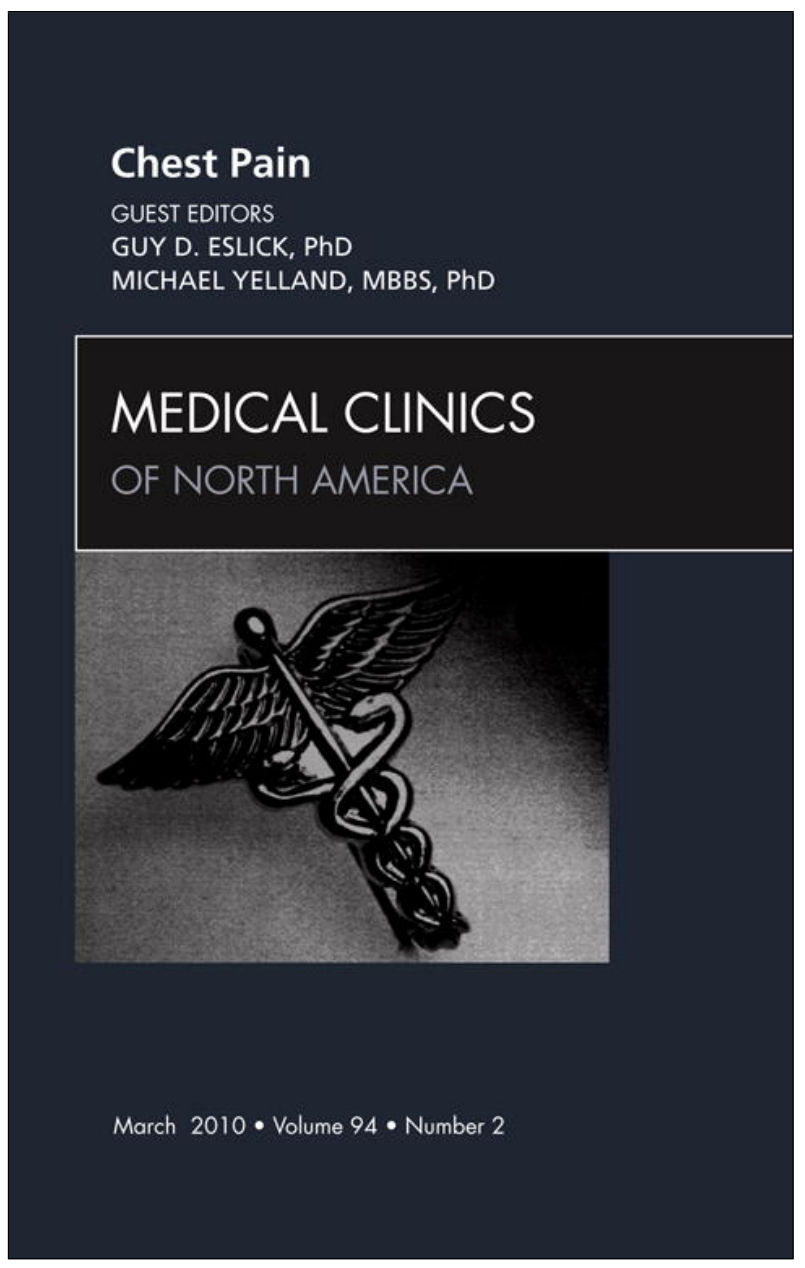

This article appeared in a journal published by Elsevier. The attached copy is furnished to the author for internal non-commercial research and education use, including for instruction at the authors institution and sharing with colleagues.

Other uses, including reproduction and distribution, or selling or licensing copies, or posting to personal, institutional or third party websites are prohibited.

In most cases authors are permitted to post their version of the article (e.g. in Word or Tex form) to their personal website or institutional repository. Authors requiring further information regarding Elsevier's archiving and manuscript policies are encouraged to visit:

http://www.elsevier.com/copyright 


\section{An Algorithm for the Diagnosis and Management of Chest Pain in Primary Care}

Michael Yelland, MBBS, PhD, FRACGP, FAFMM, Grad Dip Musculoskeletal Medicine $^{a, *}$, William E. Cayley Jr, MD, MDiv ${ }^{b}$,

Werner Vach, Dip Stats, $P h D^{C}$

\section{KEYWORDS}

- Chest pain • Algorithm • Diagnosis • Evidence

\section{BACKGROUND AND SIGNIFICANCE}

In response to the demands that chest pain assessment has placed on the health system, chest pain assessment protocols and services have been established in several countries to provide more effective and cost-efficient methods of dealing with the assessment and management of chest pain. Many of them are focused on risk stratification for life-threatening causes of chest pain, for example the Rouan decision rule for myocardial infarction (MI) ${ }^{1}$ or the Wells score for pulmonary embolism $(\mathrm{PE}){ }^{2}$ These protocols are mostly oriented toward use in the emergency department setting. They need some adaptation to make them relevant to the primary care setting, in which the spectrum of causes of chest pain is different to that in the emergency setting. ${ }^{3}$ The emergency department protocols generally do not venture into the diagnosis of other causes of chest pain that are not life threatening, commonly referred to as noncardiac chest pain (NCCP). ${ }^{4}$

The diagnosis of NCCP is challenging as it is a condition with many causes; individuals may have more than 1 cause of NCCP or have chest pain from cardiac and noncardiac causes simultaneously. History, examination, and investigations all have limited sensitivity and specificity and a definitive pathology often difficult or impossible to define. The noncardiac causes of chest pain have been classified broadly as

\footnotetext{
a School of Medicine, Logan Campus, Griffith University, University Drive, Meadowbrook, Queensland 4131, Australia

b University of Wisconsin Department of Family Medicine, UW Health Eau Claire Family Medicine Residency, 617 West Clairemont, Eau Claire, WI 54701, USA

c Institute of Medical Biometry and Medical Informatics, University Medical Center Freiburg,

Stefan Meier Straße 26, Freiburg 79104, Germany

* Corresponding author.

E-mail address: m.yelland@griffith.edu.au
} 
gastroenterologic, soft-tissue, musculoskeletal, pulmonary, and psychiatric. ${ }^{5}$ The morbidity in this group with NCCP is considerable. ${ }^{4,5}$ There has been a debate in the literature about how to deal with these patients once coronary artery disease (CAD) has been excluded. Some propose that providing a definitive diagnosis may be less important than addressing the patients' fears by providing an explanation and reassurance. ${ }^{6}$ They call for the development of better, noninvasive algorithms for use by general practitioners to avoid unnecessary referrals to hospital. Others strongly endorse the importance of a definitive diagnosis and argue that the inability to provide a definitive diagnosis may relate to the psychological and psychiatric complications of chest pain. ${ }^{7}$ They claim that it is possible to achieve this in up to $85 \%$ of cases. If this is indeed possible, there may be opportunities to develop better algorithms for positive diagnosis coupled with good-quality explanation, reassurance, and medical management of chest pain to reduce the physical and psychological morbidity of NCCP and the associated costs to the individual and the health system.

Few algorithms are designed to guide practitioners on all major causes of chest pain, particularly in the outpatient primary care setting. Cayley ${ }^{8}$ has devised an algorithm derived from the best available evidence, incorporating the Rouan rule for $\mathrm{MI},{ }^{1}$ the Wells score for PE, ${ }^{2}$ a 2 -question screen for panic disorder, ${ }^{9}$ and selective symptoms and signs with the best, albeit limited, diagnostic usefulness. However, it does not fully address diagnosis of gastroenterologic, musculoskeletal, soft-tissue, and psychological causes of chest pain. This article updates and expands this algorithm to provide the primary care practitioner with a flexible, efficient, and evidence-based approach to the primary care patient with chest pain. The algorithm covers the common causes and the rare but life-threatening causes and is based on several principles that translate evidence into practice and that also recognize the realities of working in primary care.

\section{PRINCIPLES UNDERPINNING THE CHEST PAIN ALGORITHM}

Given the large number of potential causes of chest pain in primary care and multiple clinical features and investigations used for the diagnosis or exclusion of each cause, the authors have devised an algorithm that guides the diagnostic processes for chest pain in primary care. This algorithm combines problem-solving and decision-making approaches. ${ }^{10}$ In the problem-solving approach, clinical features lead to a limited number of hypotheses based on pattern recognition, spot diagnosis, and clinical experience. These hypotheses inform subsequent information gathering. In the decision-making process, the diagnosis is refined using probabilistic reasoning. ${ }^{11}$ Probabilistic reasoning is based on knowledge of the pretest probability or prevalence of a condition and how this translates to the posttest probability based on knowledge of the diagnostic accuracy of the clinical feature or test. This principle is often not applied explicitly by exact computation of posttest probabilities, but in a more informal, implicit manner following 2 basic rules in deciding between 2 possible causes with a positive diagnostic test result:

1. If the 2 possible causes have equal prevalence, but the diagnostic tests differ in their accuracy, prioritize the cause with the better test.

2. If the 2 diagnostic tests have equal accuracy, prioritize the cause with the higher prevalence.

The algorithm presented in Fig. 1 describes a logical order to diagnosis that is safe, efficient, and comprehensive. A key consideration for safety in diagnosis is to start by assessing conditions that have the potential to threaten life. Similar to the assessment 


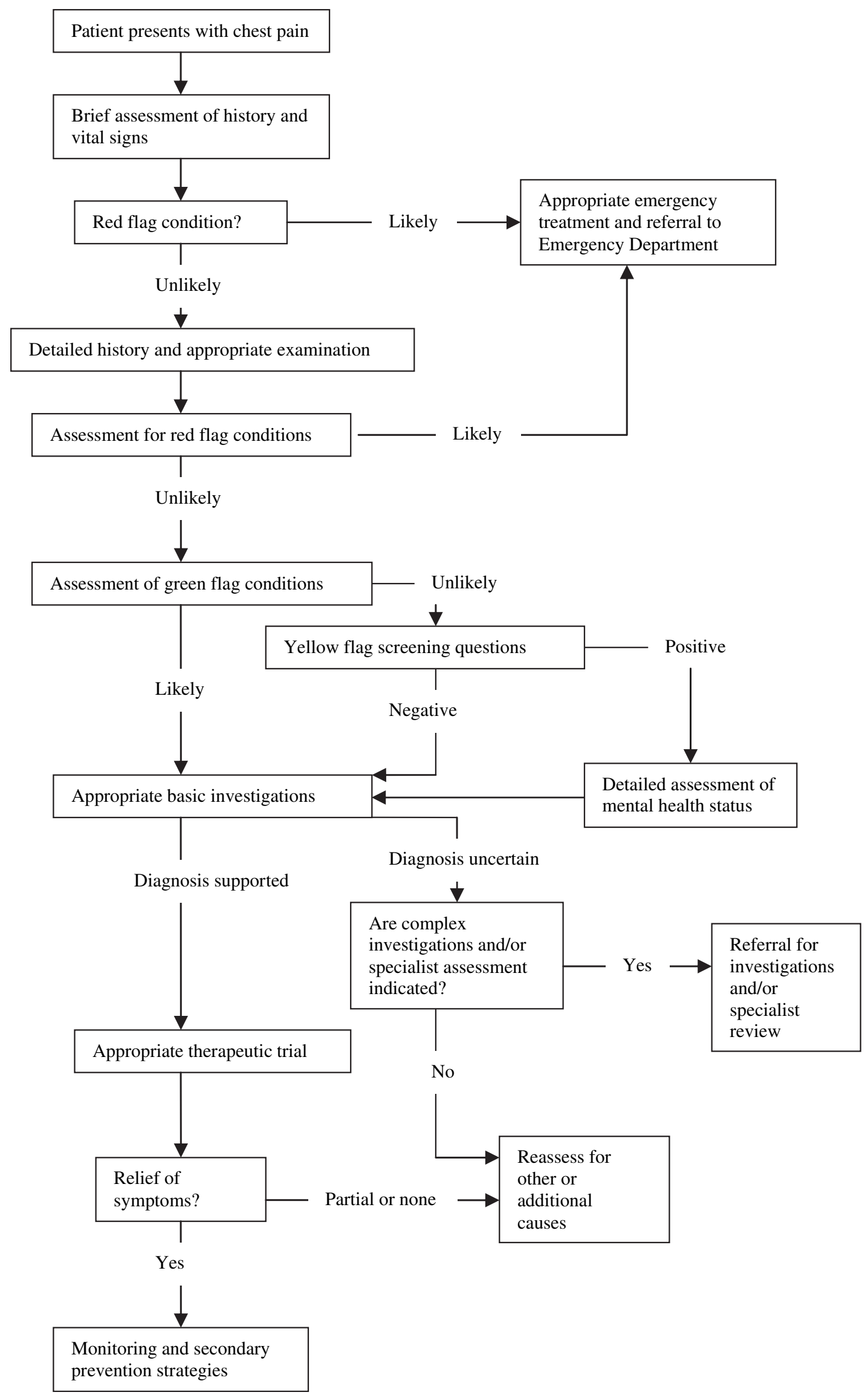

Fig. 1. Algorithm for assessment of chest pain in primary care. The key elements for use in the algorithm are summarized in Tables 6, 7 and 8. The algorithm proposed here, although based on available evidence, does not constitute a validated decision rule. 
of low back pain, indicators of life-threatening physical causes are labeled as red flags, indicators of non-life-threatening physical causes as green flags, and psychosocial indicators as yellow flags. ${ }^{12}$ The assessment of red flags takes priority over green and yellow flags. The assessment of green flags comes next, and it is the step in which the principle of probabilistic reasoning is most prominent. As all potential green flag conditions are of equal medical importance (in the sense of their need to be treated), and as the diagnostic elements of the green flags can be easily performed, it is reasonable to consider these potential causes simultaneously and to select the most likely causes for further consideration. Although assessment of yellow flags may occur throughout the consultation, decisions about their contribution to the sensation of chest pain are left until after the green flags have been adequately assessed, with the intention of increasing the diagnostic confidence about psychogenic causes or factors.

The key diagnostic elements used in the processes of the algorithm are described and tabulated later in this article. Here, the term "element" includes various symptoms, signs, and investigations or diagnostic rules or scores based on pieces of diagnostic information. A diagnostic element may also include a pragmatic trial of treatment, in which the response may support or refute a provisional diagnosis.

In choosing the elements for use in the algorithm, several properties of the elements in the primary care setting have been considered. These elements include their diagnostic performance, risks, benefits, cost, and usefulness.

\section{Diagnostic Performance}

\section{Single history, examination, and investigation elements}

The diagnostic performance of single elements with positive or negative results is variously described by the properties of sensitivity and specificity, positive and negative likelihood ratios (LRs), positive and negative predictive values, and odds ratios. Definitions of these terms can be viewed at http://www.cebm.utoronto.ca/glossary/index. htm\#s. Positive predictive value expresses the probability that the disease is present when the test is positive. A high positive predictive value is desirable in the early phase of the algorithm to make quick and accurate decisions about treatment; however, a lower positive predictive value is acceptable later in the algorithm when making decisions about therapeutic trials for low-risk conditions. The negative predictive value expresses the probability that the disease is absent when the test is negative. This factor is most important for ruling out red flag causes confidently early in the algorithm but also later to rule out additional diagnoses.

\section{Clinical prediction rules}

Clinical prediction rules (CPRs), also called diagnostic rules or diagnostic scores, aim to quantify the contribution of history, physical examination and diagnostic tests and stratify patients into levels of probability of having a condition. ${ }^{13}$ A validated CPR offers more diagnostic confidence than an unvalidated rule.

\section{Accessibility}

The following considerations affect the accessibility of elements to primary care physicians.

\section{Cost}

Lower cost elements, such as clinical assessment and simple surgery tests, are preferred but when an expensive investigation has a high diagnostic accuracy that leads to definitive diagnosis, this may be incorporated. 


\section{Time}

Because of the time constraints in primary care, elements that are simpler and more rapidly administered are favored. With respect to tests or treatments, elements with a more rapid response time are more useful diagnostically.

\section{Resources}

Equipment, if needed for the element, should be available in primary care. If it is not widely available, such as bedside troponin testing, an alternative, such as laboratory testing, should be considered.

\section{Level of training required}

The element should be able to be performed in primary care. If the level of training is higher than that generally present in the primary care setting, the element should be included only as an option with an alternative.

\section{Risks Versus Benefits}

\section{Risks}

The risk of adverse events is balanced against the potential benefits of diagnostic and treatment elements of the algorithm. Higher risks are more acceptable for red flag causes than for green or yellow flag causes. The risk of missing a red flag cause by not including an element is also a consideration.

\section{Benefits}

Benefits include reassurance as well as relief of symptoms and reduction of risk of future events. With therapeutic trials, the size of the treatment effect and the predictive value of a response to treatment, if available, will influence their inclusion in the algorithm.

\section{Diagnostic Confidence}

In the process of applying the algorithm, there will be branching points with decisions about the use of an expensive or high-risk test or therapeutic trial that will be affected by the diagnostic confidence at that point. For example, patients who are categorized as at high risk of acute coronary syndrome (ACS) will have a strong indication for referral for coronary angiography.

\section{Quality of Evidence}

This article uses the strength of recommendation taxonomy (SORT) for clinical review articles based on the quality and consistency of available evidence (http://www.aafp. org/online/en/home/publications/journals/afp/afpsort.html). ${ }^{14}$

$A=$ consistent, good-quality patient-oriented evidence

$\mathrm{B}=$ inconsistent or limited-quality patient-oriented evidence

$\mathrm{C}=$ consensus, disease-oriented evidence, usual practice, expert opinion, or case series for studies of diagnosis, treatment, prevention, or screening.

In the interests of efficiency, we have limited the choice of elements to those with the best evidence or at least some evidence supporting them. Despite this the level of evidence for many elements, particularly those related to NCCP, is still only at level C.

\section{The Epidemiology of Chest Pain in Primary Care}

Patients with chest pain place a considerable burden on the health systems of many countries. The proportion of general practice consultations for chest pain varies from at least $1 \%$ in the United Kingdom ${ }^{15}$ to $1.5 \%$ in Sweden ${ }^{16}$ and $2.7 \%$ in Switzerland. ${ }^{17}$ 
In the British general practice setting the rate of new diagnoses of chest pain has been estimated at 15.5 per 1000 person-years. ${ }^{18}$

The diagnostic probabilities across the spectrum of causes depend on the setting. The prevalences of diagnostic categories for chest pain in primary care have been defined for at least 3 countries, based on studies of often unvalidated medical diagnoses from medical records and patient questionnaires (Table 1). In Belgium they have been compared with the spectrum of chest pain diagnoses in a hospital emergency department setting, highlighting some major differences. Cardiac diagnoses accounted for $54 \%$ in hospital compared with $13 \%$ in primary care. ${ }^{3}$ Of the noncardiac causes, musculoskeletal chest pain comprised $6 \%$ of hospital diagnoses compared with $21 \%$ in primary care. Pulmonary diagnoses accounted for $12 \%$ in hospital compared with $20 \%$ in primary care but only $20 \%$ of the latter were serious diagnoses (ie, pneumonia, pleuritis, pneumothorax, and lung cancer) and the remainder were for tracheitis or bronchitis. Over the 3 countries, musculoskeletal diagnoses comprised $21 \%$ to $51 \%$ of totals, making them the most common amongst the noncardiac categories. $3,17,19$ The prevalence of gastroenterologic diagnoses was $8 \%$ to $19 \%$ and of psychogenic diagnoses was $8 \%$ to $17 \%$.

The key diagnostic elements for specific causes of chest pain are outlined in the following section. In the spirit of probabilistic reasoning we have addressed them in order of decreasing prevalence within each diagnostic category. However, as we were unable to find comparative data on the prevalence of many of these specific causes, the estimates of prevalence for some causes are based on our clinical experience.

\section{DIAGNOSTIC ELEMENTS FOR COMMON CAUSES OF CHEST PAIN IN PRIMARY CARE Cardiovascular Causes}

\section{ACS}

Three key clinical features of chest pain can help predict the risk of CAD: (1) location (is it substernal chest pain?), (2) aggravating factors (is it exertional?), and (3) alleviating factors (is it relieved by rest or nitroglycerin?). Chest pain with all 3 characteristics is considered angina chest pain, and is high risk for CAD in all age groups. If only 2 of

\begin{tabular}{|c|c|c|c|c|}
\hline Diagnosis & $\begin{array}{l}\text { Primary Care } \\
(\text { USA) })^{18}(\%)\end{array}$ & $\begin{array}{l}\text { Primary Care } \\
\text { (Switzerland) }^{16} \\
(\%)\end{array}$ & $\begin{array}{l}\text { Primary Care } \\
\text { (Belgium) }^{3}(\%)\end{array}$ & $\begin{array}{l}\text { Emergency } \\
\text { Department } \\
\text { (Belgium) }{ }^{3}(\%)\end{array}$ \\
\hline Cardiovascular $^{a}$ & 16 & 16 & 13 & 54 \\
\hline Musculoskeletal & 36 & 51 & 21 & 6 \\
\hline Pulmonary & 5 & 10 & 20 & 12 \\
\hline Gastroenterologic & 19 & 8 & 10 & 3 \\
\hline Psychogenic & 8 & 11 & 17 & 9 \\
\hline Total noncardiac & 68 & 80 & 68 & 30 \\
\hline Other & & & 10 & 10 \\
\hline $\begin{array}{l}\text { Uncertain/not } \\
\text { specified }\end{array}$ & 16 & 4 & 1 & 5 \\
\hline
\end{tabular}

a Including pulmonary embolism. 
the 3 characteristics are present, chest pain is considered atypical angina, which carries intermediate risk for CAD in women older than 50 years and in all men. Nonanginal chest pain, with only 1 of the 3 characteristics present, carries intermediate risk for CAD in women older than 60 years and men older than 40 years. ${ }^{20}$

Patients whose chest pain puts them at moderate to high risk of CAD deserve prompt assessment for the risk of ACS. ACS includes acute myocardial infarction (AMI) and unstable angina. However, studies in emergency department settings show that only a few features of angina chest pain have adequate usefulness to meaningfully increase or decrease the diagnostic likelihood of AMI. Exertional chest pain (LR 2.35) and pain radiating to the shoulder or both arms (LR 4.07) increase the likelihood of AMI. Similarly, exertional chest pain (LR 2.06), and pain radiating to the shoulder, the left arm, or both arms (LR 1.62) are the features most predictive of any ACS. ${ }^{21}$ Symptoms that are not predictive for either ACS or AMI include the site or nature of the pain and the presence of nausea, vomiting, or diaphoresis. ${ }^{22}$ The only physical finding that is helpful in diagnosis of ACS or MI is chest wall tenderness. Presence of chest wall tenderness (LR 0.3) or reproduction of chest pain with palpation (LR 0.23 ) both significantly decrease the likelihood that chest pain is caused by ACS or AMI. ${ }^{22,23}$

The most important initial test for the patient at risk of ACS or AMI is an electrocardiogram (ECG). Electrocardiographic findings that most strongly suggest ACS or AMI are new ST segment increase (LR 16), new $Q$ waves (LR range, 8.7), and a new conduction defect (LR 6.3). Although a normal ECG result markedly decreases the likelihood of an MI (LR range, 0.1-0.3), no ECG abnormality is sensitive enough for AMI or ACS that its absence completely excludes the diagnosis. ${ }^{24}$

The Rouan decision rule can help predict which patients with chest pain and a normal or nonspecific ECG are at higher risk for MI (Table 2). ${ }^{1}$ However, emergency department data indicate that up to $3 \%$ of patients initially diagnosed with a noncardiac cause of chest pain suffer death or MI within 30 days of presentation; thus patients with cardiac risk factors such as male sex, greater age, diabetes, hyperlipidemia, previous CAD, or heart failure warrant close follow-up. ${ }^{25}$

The most common markers of myocardial damage are creatine kinase (CK), its $M B$ subform (CKMB), troponin T (TnT), and troponin I (Tnl). A CKMB level greater than 6.0 $\mathrm{ng} / \mathrm{mL}$ within 9 hours of presentation for emergency care modestly increases the likelihood of $\mathrm{Ml}$ or death in the next 30 days. ${ }^{26}$

Increased levels of either troponin (TnT $>2 \mathrm{ng} / \mathrm{mL}$ or $\mathrm{Tnl}>1 \mathrm{ng} / \mathrm{mL}$ ) support the diagnosis of MI or ACS and increase the likelihood of death or recurrent MI within 30 days. Increase of troponin takes 4 to 6 hours and may remain increased for 5 to 14 days. $^{27}$

\begin{tabular}{|c|c|c|}
\hline Clinical Characteristics & $\begin{array}{l}\text { No. of Factors } \\
\text { Present }\end{array}$ & Risk of MI (\%) \\
\hline Age $>60$ years & 0 & Up to 0.6 \\
\hline Male gender & 1 & Up to 3.4 \\
\hline Pain described as pressure & 2 & Up to 4.8 \\
\hline Pain radiates to arm, shoulder, neck or jaw & 3 & Up to 12 \\
\hline Diaphoresis & 4 & Up to 26 \\
\hline \multicolumn{3}{|l|}{ History of previous $\mathrm{MI}$ or angina } \\
\hline
\end{tabular}

Data from Rouan GW, Lee TH, Cook EF, et al. Clinical characteristics and outcome of acute myocardial infarction in patients with initially normal or nonspecific electrocardiograms (a report from the Multicenter Chest Pain Study). Am J Cardiol 1989;64:1087-92. 
A survey of New Zealand general practitioners found that the majority ordered troponins at least once monthly and would be more likely to use this test if the likelihood of AMI was less than $5 \%$, or the pain was more than 12 hours ago. ${ }^{28}$ One study of 773 patients presenting to an emergency department with chest pain and an essentially normal ECG found that for detection of AMI, the sensitivity of TnT was $94 \%$ and of Tnl was $100 \%$. The specificity of the 2 assays was $99.7 \%$ and $98.9 \%$, respectively (ie, only $0.3 \%$ with a normal Tnl and $1.1 \%$ with a normal TnT at 6 hours died or had acute $\mathrm{Ml}$ in the next 30 days). ${ }^{29}$

In the detection of MI in the emergency department without ST segment increase on presentation, a normal level of TnT and of Tnl between 6 and 72 hours after the onset of chest pain is strong evidence against MI or ACS, particularly if the ECG is normal or near normal. ${ }^{30,31}$ Thus, individuals with chest pain and a low-risk history, a normal or near-normal ECG, and normal troponins can safely be evaluated as outpatients.

Potential hazards of using troponin in the primary care setting include possible delays in appropriate referral of patients with ACS to an emergency department setting, ${ }^{28}$ and a false-negative result if the test is performed too early. ${ }^{27}$

Several studies in the emergency department setting have found that the response of chest pain to administration of nitroglycerin does not reliably predict the presence or absence of cardiac chest pain, CAD, or myocardial ischemia. ${ }^{32-35}$

\section{PE}

No individual signs or symptoms can reliably diagnose PE, but a validated clinical prediction rule can help determine which patients have low, moderate, or high likelihood of PE, which then guides further evaluation. The Wells clinical prediction rule (Table 3 ) has been subjected to more than 10 years of testing and development, and validated in numerous settings. ${ }^{36-39}$ Other clinical prediction rules have been developed and validated, but to date the Wells rule is the most widely tested.

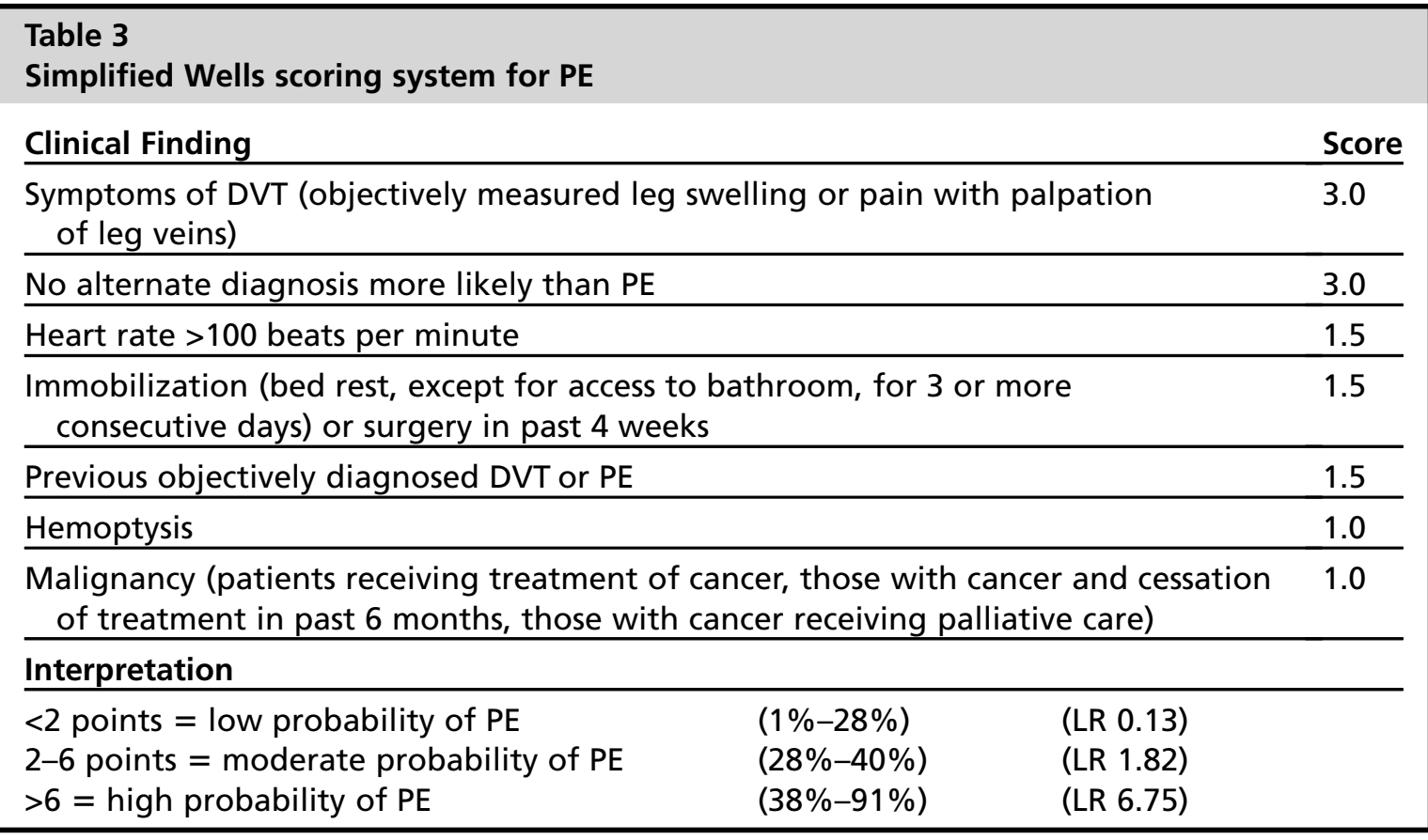

Data from Wells PS, Anderson DR, Rodger M, et al. Derivation of a simple clinical model to categorize patients probability of pulmonary embolism: increasing the models utility with the SimpliRED D-dimer. Thromb Haemost 2000;83:416-20. 
D-dimer testing has also become an important part of the evaluation for PE and deep vein thrombosis (DVT), but not all assays are the same; quantitative enzymelinked immunosorbent assay (ELISA) D-dimer assays are more sensitive, and have been more thoroughly tested in clinical settings, than whole-blood agglutination assays. ${ }^{40}$ A low clinical suspicion for PE (eg, a Wells score <2) plus a normal quantitative ELISA D-dimer assay safely rules out PE with a negative predictive value greater than $99.5 \%$. Helical computed tomography (CT) can be combined with clinical suspicion and other testing such as lower extremity ultrasound to rule in or rule out PE if further testing is needed. ${ }^{36,40-43}$

Several different sequential testing protocols have been proposed that all involve essentially the same elements:

1. For patients with low clinical suspicion for PE (Wells score <2) and a normal D-dimer, no further evaluation or treatment;

2. For patients with moderate or high clinical suspicion for PE (Wells score 2 or greater), and abnormal CT or venous ultrasound, treat for PE or DVT regardless of D-dimer

3. For patients with an abnormal D-dimer, plus a normal CT and venous ultrasound, consider serial ultrasound if clinical suspicion is low to moderate and pulmonary angiography if clinical suspicion is high.

Patients who are initially diagnosed as free of PE by such an approach, and are not treated, have a less than $1 \%$ chance of PE in the subsequent 3 months. ${ }^{42,44,45}$

\section{Heart failure}

Heart failure by itself is unlikely to cause chest pain, but it may accompany ACS, valvular disease, MI, or other critical cardiac conditions. A displaced apical impulse and a previous history of Ml support this diagnosis. Because virtually all patients with heart failure have exertional dyspnea, its absence is helpful at ruling out this diagnosis. ${ }^{46}$ An abnormal ECG and cardiomegaly on chest radiograph can increase the likelihood of heart failure among patients with chest pain, and increased b-type natriuretic peptide (BNP) levels have been found reliable for detecting heart failure in patients presenting with acute dyspnea. ${ }^{47-49}$ For any patient suspected of having heart failure based on clinical examination or laboratory testing, echocardiography is crucial to making the final diagnosis. ${ }^{50,51}$

\section{Aortic dissection}

Dissection of the thoracic aorta is a rare, red flag condition that occurs at a rate of only 6 to $10 / 100,000$ patient years. ${ }^{52}$ Left untreated, it has a mortality of $50 \%$ at 48 hours. The acute/sudden severe onset of pain is the cardinal feature of aortic dissection, with a sensitivity of $84 \%$. The description of the pain as ripping or tearing has an LR for aortic dissection from 1.2 to $10.8 .^{52}$ Hypertension is the most common predisposing factor, being present in $78 \%$ of patients. ${ }^{53}$

\section{Pulmonary Causes of Chest Pain}

\section{Acute bronchitis and pneumonia}

It is important to differentiate bronchitis from pneumonia, as the latter is a more severe infection that may require more aggressive treatment, including hospitalization. ${ }^{54}$ Chest radiograph is considered the reference standard test for patients suspected to have pneumonia, and is the standard against which clinical evaluations for pneumonia are compared. ${ }^{55}$ When deciding whether to proceed to chest radiograph, the presence of fever or focal chest signs such as increased vocal resonance or dullness 
to percussion are the most useful clinical tools in differentiating these 2 conditions. ${ }^{55}$ In 1 sample of patients with acute cough and a $5 \%$ to $10 \%$ prevalence of pneumonia, in whom focal auscultatory signs were present, the chance of pneumonia increased to $39 \%$, and reduced to only $2 \%$ when the signs were absent. ${ }^{56}$ The absence of focal chest findings does not completely rule out pneumonia in the patient with chest pain and cough. ${ }^{55}$ A large study in 1984 developed a decision rule (Table 4) using 7 clinical findings to predict the likelihood of pneumonia. ${ }^{57}$

A Cochrane review has shown modest benefits for treating acute bronchitis with antibiotics, including reduction in cough, days feeling unwell, and days of limited activity. ${ }^{58}$ There is a stronger indication for treating those subgroups at high risk of complications including those aged more than 75 years, and those with insulin-dependent diabetes, preexisting chronic obstructive pulmonary disease, cardiac failure, and serious neurologic disorders. ${ }^{58}$

\section{Lung cancer}

Chest pain is a presenting symptom in $53 \%$ of patients with lung cancer. ${ }^{59}$ Respiratory symptoms with a higher frequency at presentation include dyspnea (86\%), cough $(81 \%)$, hoarseness $(54 \%)$, and hemoptysis $(26 \%)$. None of these symptoms are diagnostic of lung cancer, but other common symptoms, such as tiredness (86\%) and lack of appetite (76\%), are too general to indicate lung cancer, let alone a respiratory cause of any kind.

Smoking is the major risk factor for lung cancer, with hazard ratios (compared with those who have never smoked) ranging from 2 for former smokers to 55 for heavy smokers. ${ }^{60}$ One review has summarized that the relative risk of developing lung cancer in ever-smokers is 24.2 for men and 12.5 for women. ${ }^{61}$

Sputum cytology, a test that can readily be arranged in primary care, has a specificity of $99 \%$ and a sensitivity of $66 \%$ in the detection of lung cancer. ${ }^{62}$ Further investigation requires referral for bronchoscopy, cytobrushing, transbronchial biopsy, or transthoracic needle aspirate.

\section{Pneumothorax}

Pneumothorax is a rare, red flag cause of chest pain, with an incidence of 14 per 100,000 person-years in men and 3 per 100,000 years in women. ${ }^{63,64}$ Spontaneous

\begin{tabular}{|c|c|c|c|c|c|}
\hline \multirow[b]{3}{*}{ Finding } & \multirow[b]{3}{*}{ Points } & \multicolumn{4}{|c|}{ Interpretation } \\
\hline & & \multirow[b]{2}{*}{ Score } & \multicolumn{2}{|c|}{ LR } & \multirow{2}{*}{$\begin{array}{l}\text { Probability of } \\
\text { Pneumonia (\%) }\end{array}$} \\
\hline & & & $\operatorname{LR}(+)$ & $\operatorname{LR}(-)$ & \\
\hline Rhinorrhea & -2 & & & & \\
\hline Sore throat & -1 & & & & \\
\hline Night sweats & 1 & -3 & 1.1 & 0 & 5 \\
\hline Myalgia & 1 & -1 & 2.5 & 0.37 & 12 \\
\hline Sputum all day & 1 & 0 & 4.9 & 0.47 & 21 \\
\hline $\begin{array}{l}\text { Respiratory rate }>25 \text { breaths } \\
\text { per minute }\end{array}$ & 2 & 1 & 8.3 & 0.70 & 30 \\
\hline Temperature $>100^{\circ} \mathrm{F}$ & 2 & 3 & 11 & 0.90 & 37 \\
\hline
\end{tabular}

Data from Diehr P, Wood RW, Bushyhead J, et al. Prediction of pneumonia in outpatients with acute cough-a statistical approach. J Chronic Dis 1984;37:215-25. 
pneumothorax may be primary (usually in the 20- to 40-year age-group) or secondary to underlying pulmonary disease (usually in the 60 years and older age-group). Other causes of pneumothorax are chest trauma and medical procedures. Acute, pleuritic chest pain and dyspnoea occur together in $64 \%$ to $85 \%$ of patients. ${ }^{64}$ Signs of tachycardia are most common followed by tachypnea and hypoxia. Diagnosis is by chest radiograph, ultrasound, or CT scan.

\section{Musculoskeletal Chest Wall Pain}

Most musculoskeletal chest wall pain is labeled by an umbrella term chest wall syndrome, which encompasses a range of diagnostic labels including anterior chest wall syndrome, atypical chest pain, musculoskeletal chest pain syndrome, cervicothoracic angina (CTA), and costochondritis. ${ }^{17}$ All of these diagnoses are clinically based and lack a true reference standard for diagnosis, such as a radiological or pathologic test. The cause of chest wall syndrome is poorly understood. Musculoskeletal chest pain caused by trauma is discussed separately to the chest wall syndrome, as is that associated with the generalized pain syndrome labeled fibromyalgia.

\section{Chest wall syndrome}

In a Swiss primary care cohort study of 672 patients with chest pain, ${ }^{17}$ using a standardized history and examination protocol, $45 \%$ were diagnosed with conditions that fell within the broad category of chest wall syndrome. The clinical characteristics that best discriminated this syndrome from other causes of chest pain were chest wall pain reproducible by palpation, chest pain that was neither squeezing nor oppressive, pain localized to left chest wall, nonexercise-induced chest pain, pain influenced by mechanical factors or simply well localized on the chest wall (Table 5). Diagnoses were not validated by other clinicians or investigations.

In an Australian study of musculoskeletal signs comparing patients from primary care with pain in the chest or abdomen with pain-free controls, the prevalence of pain with cervical and thoracic spinal movements was $60 \%$ to $70 \%$ versus $20 \%$ to $35 \%$ and thoracic spinal tenderness was $65 \%$ versus $25 \% .{ }^{65}$

Further useful information on clinical features of musculoskeletal pain comes from hospital studies of patients with chest pain undergoing coronary angiography. In an early study of patients with chest pain and negative coronary angiography, chest wall tenderness was found in $69 \%$ of patients compared with none of a control group without chest pain. ${ }^{66}$ However, there was a correlation between the sites of tenderness and pain in only $23 \%$ of the case group. Christensen and colleagues $^{67}$ have

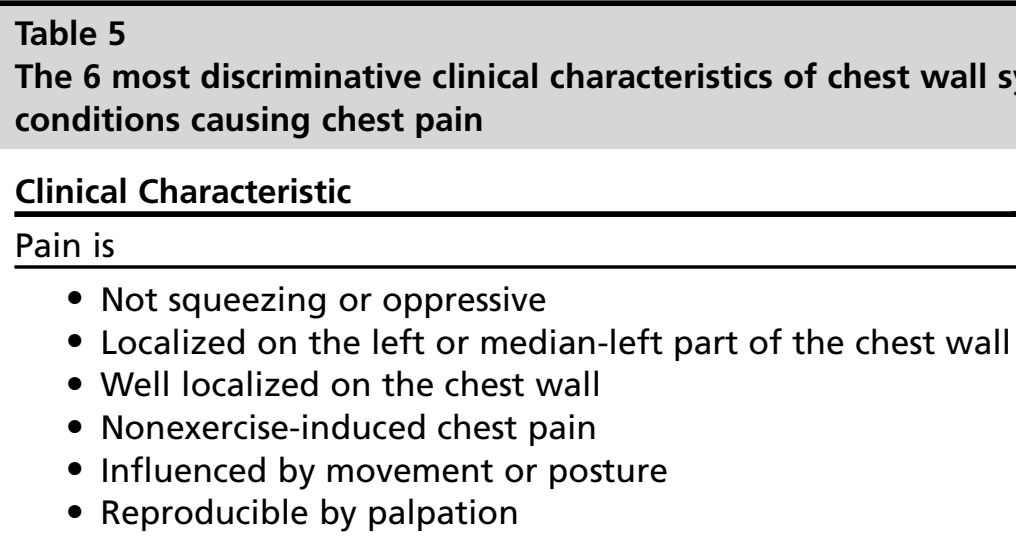


made a diagnosis of musculoskeletal chest pain labeled as CTA in $18 \%$ of a cohort of patients with known or suspected stable angina referred to a hospital for coronary angiography. This diagnosis was based on a detailed history and spinal/chest wall palpation findings and produced a group in which $80 \%$ had negative myocardial perfusion scintigraphy compared with $50 \%$ in the remaining non-CTA group. They found that combining several clinical features may be more accurate in making a musculoskeletal diagnosis than using 1 feature alone. The diagnosis of CTA is most closely associated with:

- The grading of angina by a physician as noncardiac or atypical angina (Canadian Cardiovascular Society [CCS] guidelines)

- The presence of neck pain

- Reduced motion palpation of the T3 to T5 vertebrae

- The presence of spinal tenderness.

Indirect support for the diagnosis of musculoskeletal chest pain in the CTA group came from improvements in pain and general health with a trial of manual therapy compared with no change in these parameters in those without CTA treated by other means. ${ }^{68}$ The same research team is about to publish a similar analysis of a cohort of patients with acute chest pain but with a more rigorous assessment of manual therapy using randomized clinical trial design. ${ }^{69}$

\section{Costochondritis}

Costochondritis, also called costosternal syndrome, is a condition characterized by pain and tenderness at the costochondral or chondrosternal articulations without a notable swelling as in the less common condition of Tietze syndrome. ${ }^{70}$ Usually multiple levels are affected and they lack swelling or induration. Pain is reproduced by palpation of the affected cartilage segments and may radiate on the chest wall.

Corticosteroid injections have been used as a treatment of costochondritis with sulfasalazine added for recurrent cases. This approach has been shown in a retrospective case series to reduce investigation and hospitalizations for chest pain. ${ }^{71}$ Otherwise there is little research in this area. Trial of analgesics or antiinflammatory medication, rest, and reassurance has been recommended, but there are no data about their efficacy. ${ }^{72}$

\section{Trauma}

Chest pain may arise from ribs and muscles that have suffered direct or indirect trauma. ${ }^{70}$ This trauma is usually clear from the history. Less obvious may be rib fractures resulting from repetitive strain of coughing and also as stress fractures in sports such as golf, rowing, pitching, and bodybuilding. ${ }^{71}$ Clinical features include pain on inspiration and chest or upper limb movements and localized tenderness at the site of the strain or fracture. Not all fractures may be detected by plain radiographs, so if a clinical suspicion of fracture remains, bone scintigraphy, CT scanning, ${ }^{73}$ or ultrasonography ${ }^{74}$ may be necessary.

\section{Fibromyalgia}

Fibromyalgia is a syndrome characterized by widespread chronic muscle pain and tenderness in multiple discrete points. ${ }^{70}$ The pain must be present on both sides of the body and above and below the waist, including part of the spine or anterior chest. ${ }^{75}$ Fatigue, insomnia, and joint pains further help to characterize fibromyalgia, as they are present in more than $70 \%$ of patients. Common muscle tender points in the chest are in the pectorals, the rotator cuff, rhomboids, and trapezius. There are no serologic or histologic markers of inflammation or other pathology in this condition. Coexisting anxiety and depression may add to the pain and suffering. The key to 
screening for fibromyalgia as the cause of chest pain is to check if pain is present outside the chest and then assess if its distribution and an examination of the designated points for tenderness fit the pattern for fibromyalgia. Other rheumatologic causes of widespread pain should be excluded before diagnosing fibromyalgia.

\section{Gastroenterologic Causes of Chest Pain}

In assessing possible gastroenterologic causes of chest pain, attention should first be paid to several important symptoms that may herald serious conditions: the so-called alarm symptoms. These symptoms include repeated vomiting, decreased appetite, weight loss, dysphagia, odynophagia (pain on swallowing), hematemesis, anemia, and melena (Box 1). ${ }^{76}$

Differentiating cardiac pain from esophageal pain is difficult, but features that are more indicative of esophageal pain in the emergency department setting are an atypical response to exercise, pain that continued as a background ache, retrosternal pain without lateral radiation, pain that disturbed sleep, and the presence of certain esophageal symptoms. ${ }^{77}$ These esophageal symptoms include dysphagia and odynophagia, heartburn, and regurgitation, Of these symptoms, the only 3 significantly more common in patients with NCCP with gastroesophageal reflux disease (GERD) versus those without GERD are heartburn ( $57 \%$ vs $21 \%$ ) and regurgitation (49\% vs $16 \%)$ and pain relieved by antacid (43\% vs $16 \%$ ). ${ }^{77}$ These translate to sensitivities of $40 \%$ to $49 \%$ and specificities of $81 \%$ to $84 \%$.

Although upper gastrointestinal (Gl) endoscopy or 24-hour esophageal pH monitoring have been used as reference standards for the diagnosis of GERD, ${ }^{78,79}$ neither shows a perfect correlation with symptoms. The cheaper and more accessible alternative in primary care is an empiric trial of high-dose acid suppression using a proton pump inhibitor (PPI). The range for the sensitivity of this test is $65 \%$ to $90 \%$ and for the specificity, $75 \%$ to $88 \%$, using upper Gl endoscopy or 24-hour esophageal pH monitoring as a reference standard. ${ }^{78,80}$ Treatment success at 12 months is also higher than for endoscopy or monitoring (84\% vs $74 \%) .{ }^{81}$ Several schedules of therapeutic trials of PPIs ranging from 1 day to 4 weeks have been tested but the one with the best balance between accuracy and usefulness is a 7-day trial of lansoprazole (60 mg in the morning and $30 \mathrm{mg}$ in the evening). ${ }^{76}$ At the threshold of $50 \%$ reduction in symptoms, this test has a sensitivity of $78 \%$ and specificity of $82 \%$ in

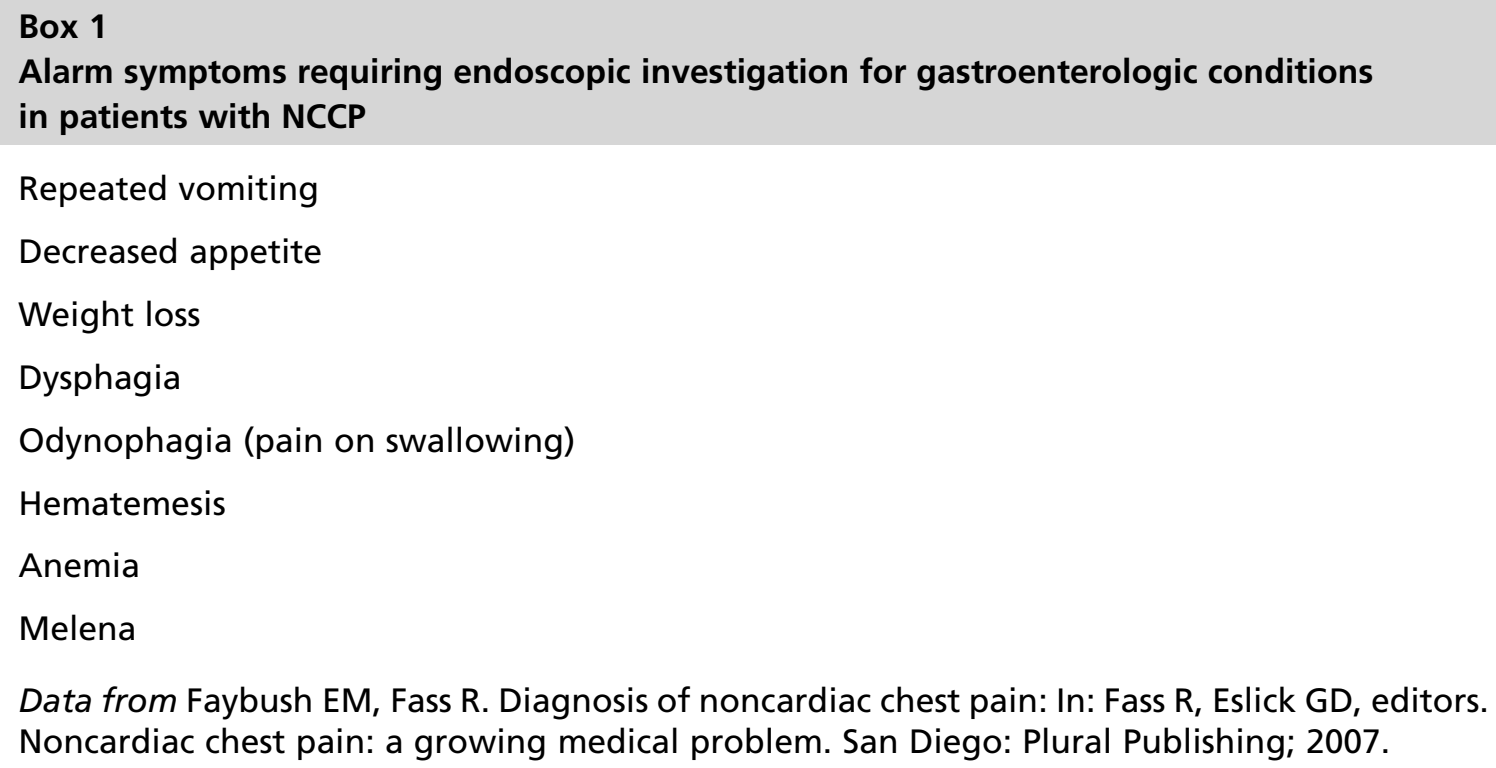

Data from Faybush EM, Fass R. Diagnosis of noncardiac chest pain: In: Fass R, Eslick GD, editors. Noncardiac chest pain: a growing medical problem. San Diego: Plural Publishing; 2007. 
the diagnosis of GERD and is able to diagnose most of the responders within the first 48 hours. Others recommend a longer PPI trial period of 1 to 2 months before investigating for other causes of chest pain (see the article by Oranu and Vaezi elsewhere in this issue for further explanation of this topic).

Failing a clear response to the PPI test, if the primary care practitioner still suspects an esophageal cause for the pain, referral is needed to a gastroenterologist for investigation of esophageal motility with esophageal manometry or visceral hyperalgesia with an intraesophageal balloon distension test. ${ }^{76}$ Alternatively, the practitioner should revisit the history and examination to check for causes other than gastroesophageal disorders.

\section{Skin and Soft-Tissue Causes}

In assessment of skin and soft tissue as a cause of chest pain, the detection of a tender skin lesion at the site of pain may uncover an obvious cause of the pain. Skin lesions such as glomus tumors, eccrine spiradenomas, leiomyomas, angiolipomas, and traumatic neuromas are unlikely to cause diagnostic uncertainty (see the article by Muir and Yelland elsewhere in this issue for further explanation of this topic). Painful breast lesions including cancer and fibrocystic disease are somewhat more difficult to detect and require deeper palpation and special tests for diagnosis. ${ }^{82,83}$ The main difficulty is in the exclusion of herpes zoster as a cause in the prodromal period of about 4 days before the emergence of skin lesions in a dermatomal distribution. The commonest symptoms in this period are dermatomal pain (41\%), itching (27\%), and paresthesia (12\%). ${ }^{84}$ Antiviral therapies given before the emergence of the rash may reduce pain during treatment and for a month after this, but have no effect on pain at 3 months and beyond. ${ }^{85}$

\section{Psychogenic Chest Pain}

The proportion with a primary diagnosis of psychogenic chest pain is difficult to estimate with any accuracy. The precise contribution of the psychiatric disorder to the chest pain is difficult to define. In an article elsewhere in this issue on psychological causes of chest pain, White avoids labeling certain types of chest pain as purely psychogenic; rather she discusses the increased likelihood of psychiatric problems in patients with NCCP, showing nearly twice the prevalence of psychiatric impairment compared with in patients with $C A D^{86}$ and 2 to 3 times the prevalence of anxiety compared with patients with cardiac disease and with the general population. The situation is made more complex by the association between stress and myocardial ischemia. In patients without documented CAD, mental stress can induce myocardial ischemia in $16 \%$ to $21 \% .^{87}$ Furthermore, in patients with documented CAD, mental stress-induced transient myocardial ischemia has been found in $34 \%$ to $74 \% .{ }^{87}$ Therefore it is prudent to view psychological disorders as contributors to the sensation of chest pain rather than the cause per se. It is also prudent to remember that psychological and physical conditions commonly coexist.

An assessment of the contribution of psychological factors to chest pain commences with a thorough assessment of the physical causes of chest pain outlined in this article followed by an assessment for panic, anxiety, and depression. Panic disorder has a reported prevalence of $8 \%$ in primary care patients with NCCP. ${ }^{88}$

Given the time constraints of primary care, the use of 2 questions as a brief diagnostic screen for panic disorder in primary care ${ }^{9}$ has been suggested to screen for underlying panic disorder. These are:

- "In the past 6 months, have you ever had a spell or an attack when all of a sudden you felt frightened, anxious, or very uneasy?" 
- "In the past 6 months, have you ever had a spell or an attack when for no reason your heart suddenly began to race, you felt faint, or you couldn't catch your breath?"

A positive response to either item is a positive screen. In a primary care setting, this brief questionnaire has good sensitivity (94\%-100\%) and negative predictive value $(94 \%-100 \%)$ so it is useful for excluding panic disorder. However, its low specificity (25\%-59\%) and positive predictive value (range 18\%-40\%) mean that a positive result requires more thorough assessment.

Similarly, there is a rapid screen for depression using the following 2 questions ${ }^{89}$ :

- "During the past month have you often been bothered by feeling down, depressed, or hopeless?"

- "During the past month have you often been bothered by little interest or pleasure in doing things?"

As with the screen for panic disorder, a positive response to 1 or both questions is regarded as positive screen. In the primary care setting this screen has a sensitivity of $97 \%(95 \%$ confidence interval [Cl], 83\%-99\%) and a specificity of $67 \%(95 \% \mathrm{Cl}$, $62 \%-72 \%)$. The associated positive LR of 2.9 (2.5-3.4) and negative LR of 0.05 $(0.01-0.35)^{89}$ make it a useful screening tool for depression.

A therapeutic trial of treatment of anxiety or depression is not only desirable to reduce the episodes of chest pain, but may act as a diagnostic tool. Several psychological interventions for NCCP are discussed elsewhere in this issue in the article by White on psychological causes of chest pain. These include cognitive behavioral therapy (CBT), hypnotherapy, relaxation training, and biofeedback. Of these, the best evidence for effectiveness in the short- and long-term is for CBT. ${ }^{90}$

Other evidence from therapeutic trials for psychological disorders is not specific to patients with chest pain, but may give some guide to treatment. For panic disorder, combined psychotherapy and antidepressant therapy is more effective than either therapy alone. ${ }^{91}$ When appropriate psychological interventions are not available or have been unsuccessful, there is a role for a trial of selective serotonin reuptake inhibitors for depression. These drugs have evidence for effectiveness compared with placebo in the primary care setting. ${ }^{92}$ They may be preferred to tricyclic antidepressants in patients with chest pain because of their lower cardiotoxicity in overdose. $^{93}$

\section{Applying the Algorithm in Practice}

The chest pain algorithm shown in Fig. 1 acts as a guiding framework for the clinical application of the diagnostic elements described in the body of this article. The diagnostic elements relating to history, examination, and investigation are summarized in Tables 6 and 7 and those relating to therapeutic trials in Table 8.

Early in the red flag algorithm it is important to take a brief history and check the vital signs to assess if emergency treatment and referral to an emergency department are necessary. If the patient seems stable, a more detailed assessment for red flag conditions can be performed, with urgent treatment and referral if red flags are found.

Not all cardiac and pulmonary causes are red flags. Certain cardiac and pulmonary causes can be safely managed in the community and may depend on the availability of community-based treatments and the ability to refer for complex investigations and specialist review if indicated. For example, a patient with stable angina can be managed with medication and referral to a cardiologist for coronary angiography. 


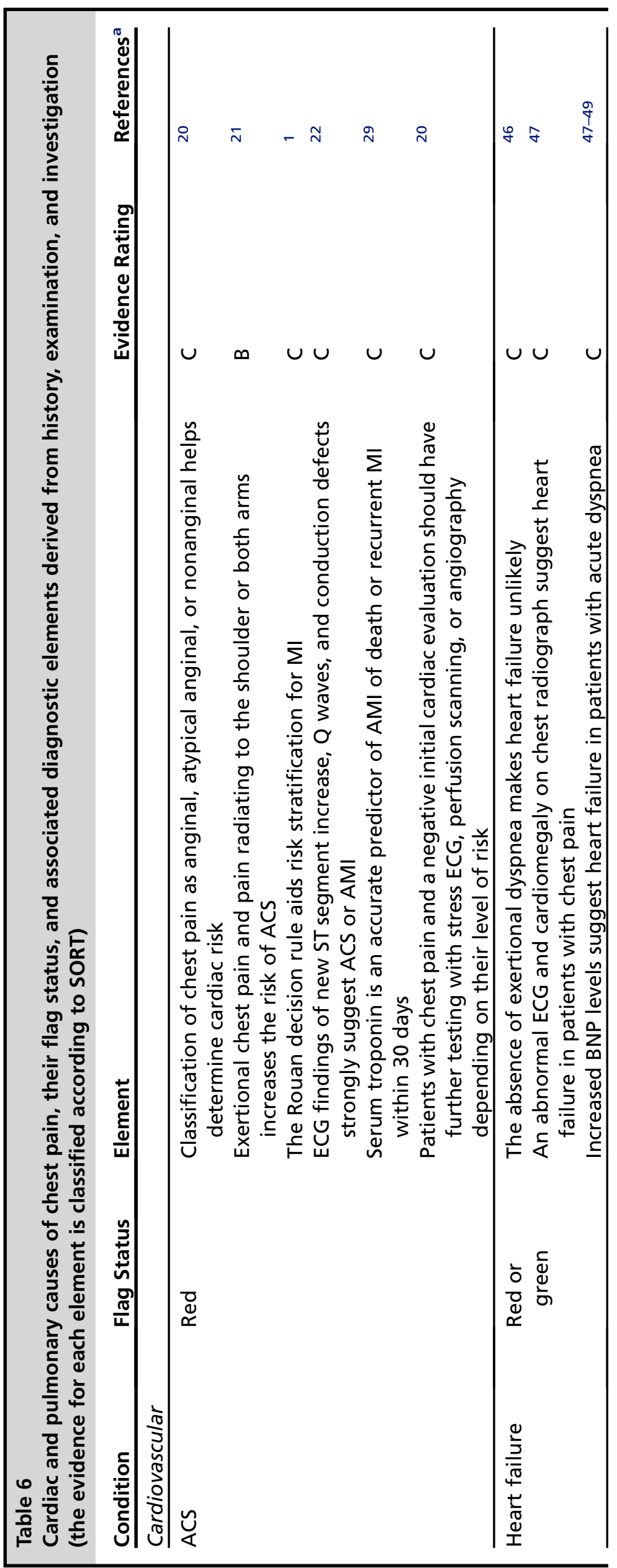




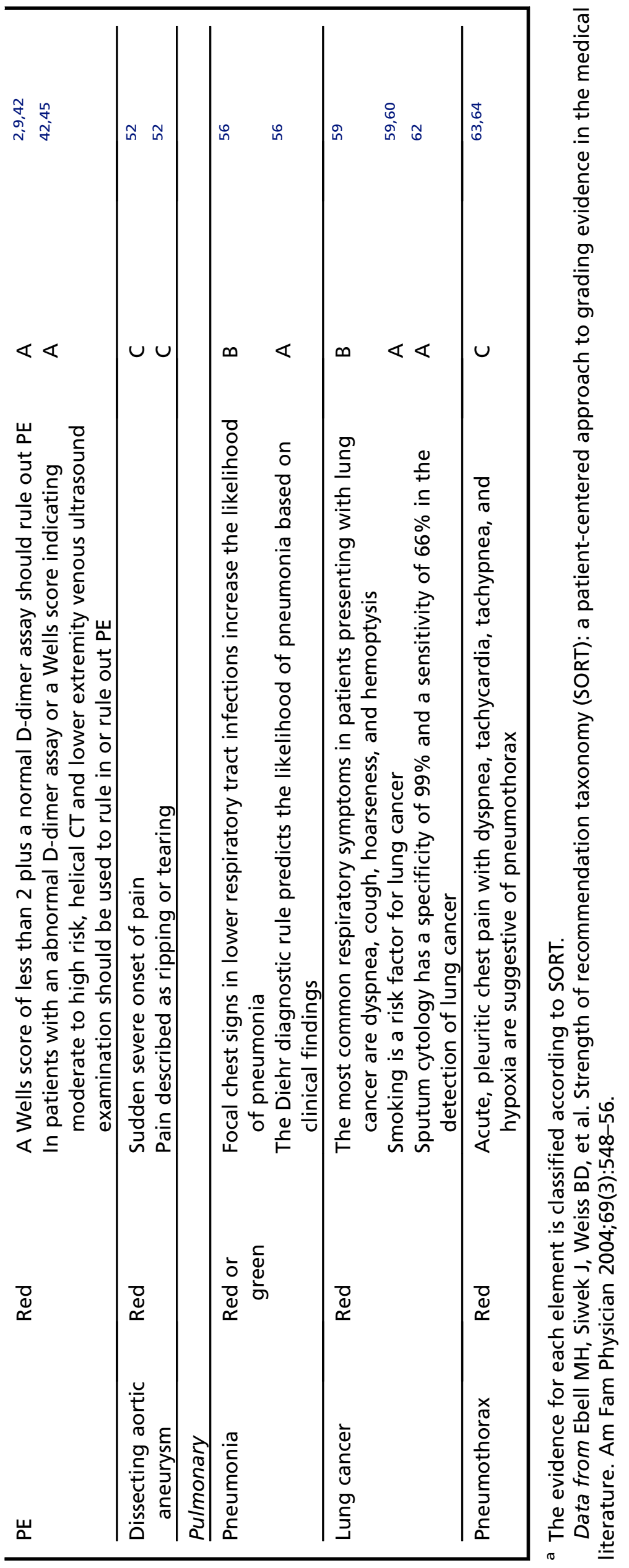




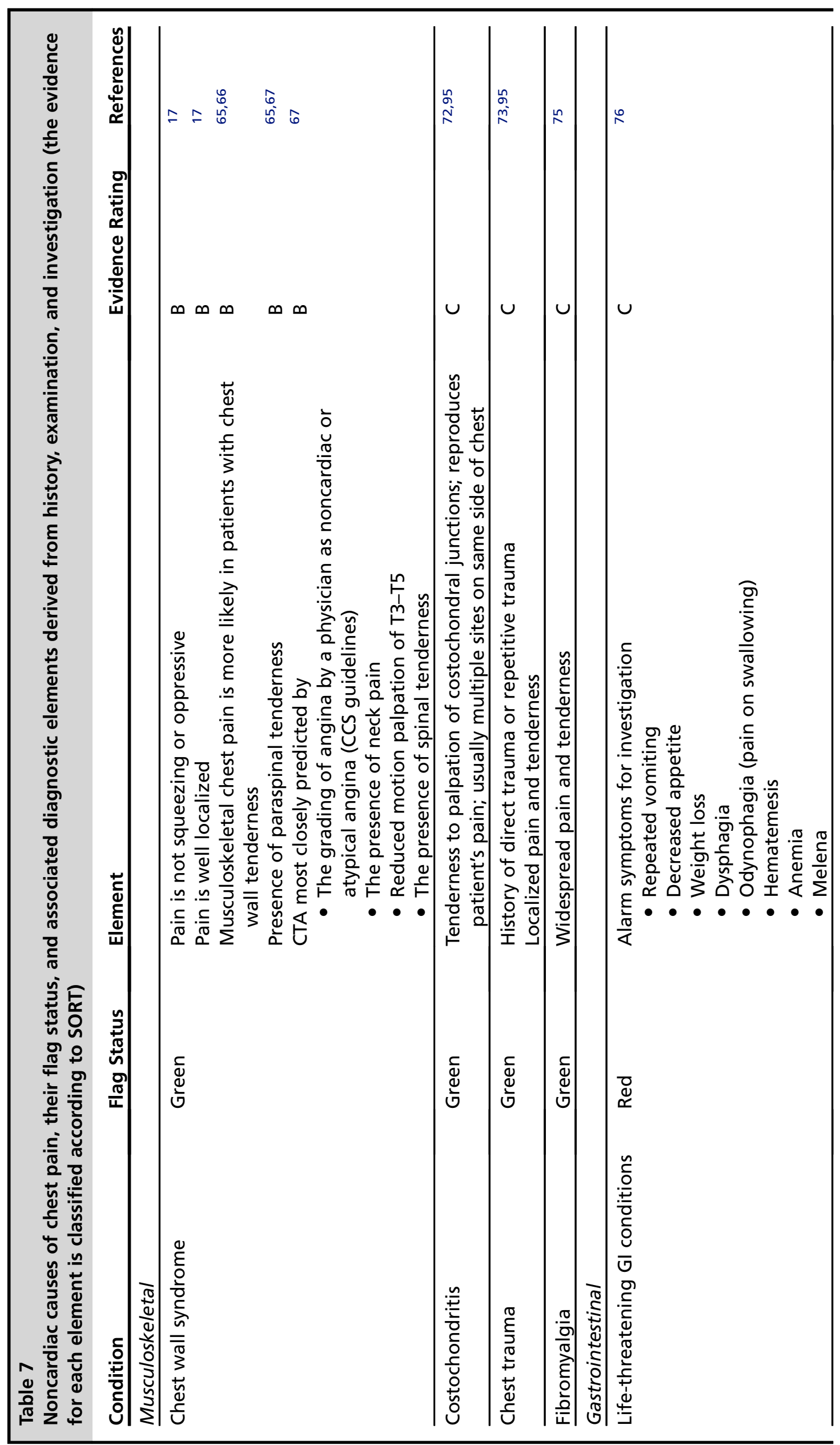




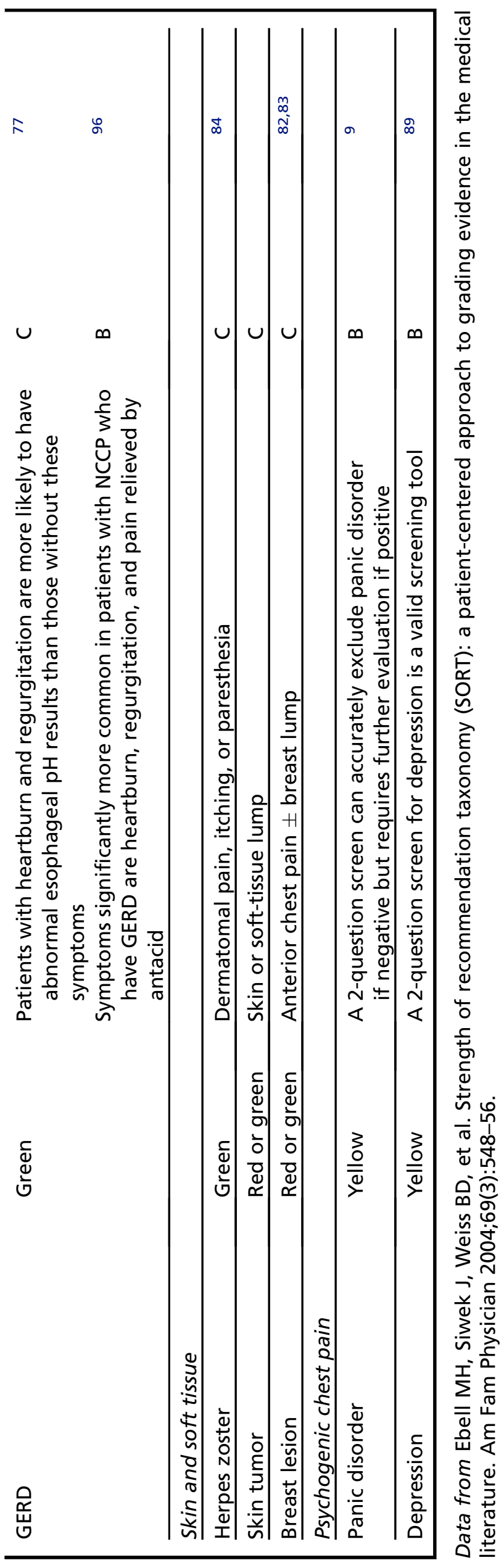




\begin{tabular}{|c|c|c|c|}
\hline \multicolumn{4}{|c|}{$\begin{array}{l}\text { Table } 8 \\
\text { Conditions causing chest pain and associated diagnostic elements derived from therapeutic } \\
\text { trials (the evidence for each element is classified according to SORT) }\end{array}$} \\
\hline Condition & Element & Evidence Rating & References \\
\hline \multicolumn{4}{|l|}{ Cardiovascular } \\
\hline ACS & $\begin{array}{l}\text { Administration of nitroglycerin } \\
\text { does not reliably predict the } \\
\text { presence or absence of cardiac } \\
\text { chest pain, CAD, or myocardial } \\
\text { ischemia }\end{array}$ & B & $32-35$ \\
\hline \multicolumn{4}{|l|}{ Pulmonary } \\
\hline \multirow{2}{*}{ Acute bronchitis } & Antibiotics have modest benefits & A & 58 \\
\hline & $\begin{array}{l}\text { Stronger indication for antibiotics } \\
\text { in groups with a high risk of } \\
\text { complications from infection }\end{array}$ & C & 54 \\
\hline \multicolumn{4}{|l|}{ Musculoskeletal } \\
\hline Chest wall syndrome & $\begin{array}{l}\text { Manual therapy in patients with } \\
\text { clinical features of } \\
\text { musculoskeletal chest pain }\end{array}$ & C & 67 \\
\hline Costochondritis & $\begin{array}{l}\text { Local anesthetic injections } \\
\text { Analgesics or antiinflammatory } \\
\text { medication, rest, and } \\
\text { reassurance }\end{array}$ & B & 71,72 \\
\hline \multicolumn{4}{|l|}{ Gastrointestinal } \\
\hline GERD & PPI for reflux esophagitis & $\mathrm{B}$ & 76 \\
\hline \multicolumn{4}{|l|}{ Skin and soft tissue } \\
\hline Herpes zoster & $\begin{array}{l}\text { Antiviral agents for herpes zoster } \\
\text { (not specific to chest pain } \\
\text { patients) }\end{array}$ & $B$ & 85 \\
\hline Skin tumor or breast lesion & $\begin{array}{l}\text { Excision of tumors (not specific to } \\
\text { chest pain patients) }\end{array}$ & $\mathrm{C}$ & \\
\hline \multicolumn{4}{|l|}{ Psychogenic } \\
\hline \multirow[t]{2}{*}{ Panic disorder } & CBT & A & 90 \\
\hline & $\begin{array}{l}\text { Combined behavioral therapy and } \\
\text { antidepressants in panic } \\
\text { disorder (not specific to chest } \\
\text { pain patients) }\end{array}$ & A & 91 \\
\hline Depression & $\begin{array}{l}\text { SSRIs for depression (not specific } \\
\text { to chest pain patients) }\end{array}$ & A & 92 \\
\hline
\end{tabular}

Data from Ebell MH, Siwek J, Weiss BD, et al. Strength of recommendation taxonomy (SORT): a patient-centered approach to grading evidence in the medical literature. Am Fam Physician 2004;69(3):548-56.

Once red flags have been assessed as unlikely, the assessment can switch to green flags. If a green flag is found, basic investigations that can be performed quickly and locally may be performed, often to deal with any remaining uncertainty about red flags. If green flags are unlikely, the brief screening questionnaires for panic disorder and depression can be used to screen for these conditions, and a more detailed assessment of the mental health status performed if they are positive. If this screening process is negative, further investigation, at least at a basic level, may be indicated to exclude green flags with more certainty. 
These assessments should lead to a provisional diagnosis and an appropriate therapeutic trial. This trial may require referral, depending on the skills of the practitioner. The response to the trial is used as a weak form of evidence to confirm or refute the provisional diagnosis. If the trial is successful, but the underlying condition is likely to continue, then follow-up should be arranged for monitoring and secondary prevention. If the trial is unsuccessful or only partly successful, the options are to search for a different cause or a second cause or to refer for further investigation and/or specialist review.

\section{A Word of Caution}

Trials of treatment are incorporated within this algorithm not only to provide treatment per se but also for their diagnostic benefit. However, throughout this process the practitioner should be mindful of investigating any symptoms suggestive of serious causes. Patients may have more than 1 cause of chest pain. Discovery of a noncardiac cause is no reason to be complacent about cardiovascular risk factors. In the emergency department setting, predictors of adverse cardiac events after an initial diagnosis of NCCP include hypercholesterolemia, diabetes, history of CAD, and history of congestive heart failure. ${ }^{25}$ These features can act as a guide to primary care practitioners for patients, and further testing to exclude cardiac causes of chest pain is warranted when these predictors are present.

The algorithm proposed here, although based on available evidence, does not constitute a validated decision rule. It warrants testing in a clinical trial in primary care, where it could be compared with usual care for chest pain.

\section{SUMMARY}

It is apt to conclude with a quote from Anthony Komaroff, who, in 1982, wrote about the concern that algorithms would threaten the art of clinical medicine, leading to regimentation and mediocrity in decision making. ${ }^{94}$ In their defense, he wrote:

In our view, algorithms can help us to articulate how we make decisions, to clarify our knowledge and to recognize our ignorance. They can help us to demystify the practice of medicine, and to demonstrate that much of what we call the "art" of medicine is really a scientific process, a science which is waiting to be articulated.

Although the science behind the assessment of chest pain into an algorithm has progressed considerably since 1982, this article illustrates that there is still a lot left to be validated about many of the diagnostic elements used in this assessment process. Nonetheless, there is now a lot of science that can inform the art of dealing with patients presenting with chest pain. The algorithm and its diagnostic elements presented should be used with discretion to guide, rather than replace, clinical decision making.

\section{REFERENCES}

1. Rouan GW, Lee TH, Cook EF, et al. Clinical characteristics and outcome of acute myocardial infarction in patients with initially normal or nonspecific electrocardiograms (a report from the multicenter chest pain study). Am J Cardiol 1989;64:1087-92.

2. Wells PS, Anderson DR, Rodger M, et al. Derivation of a simple clinical model to categorize patients probability of pulmonary embolism: increasing the models utility with the SimpliRED D-dimer. Thromb Haemost 2000;83:416-20.

3. Buntinx F, Knockaert D, Bruyninckx R, et al. Chest pain in general practice or in the hospital emergency department: is it the same? Fam Pract 2001;18(6):586-9. 
4. Eslick GD, Talley NJ. Non-cardiac chest pain: squeezing the life out of the Australian healthcare system? Med J Aust 2000;173:233-4.

5. Eslick G, Fass R. Noncardiac chest pain: evaluation and treatment. Gastroenterol Clin North Am 2003;32:531-52.

6. Nihjer G, Weinman J, Bass C, et al. Chest pain in people with normal coronary anatomy. BMJ 2001;323:1320-1.

7. Coulshed DS, Eslick GD, Talley NJ. Non-cardiac chest pain[letter to the editor]. BMJ 2002;324:915.

8. Cayley WE Jr. Diagnosing the cause of chest pain. Am Fam Physician 2005; 72(10):2012-21.

9. Stein MB, Roy-Byrne PP, McQuaid JR, et al. Development of a brief diagnostic screen for panic disorder in primary care. Psychosom Med 1999;61:359-64.

10. Elstein AS, Schwartz A. Clinical problem solving and diagnostic decision making: selective review of the cognitive literature. BMJ 2002;324(7339):729-32.

11. Doust J. Diagnosis in general practice. Using probabilistic reasoning. BMJ 2009; 339:b3823.

12. Bogduk N, McGuirk B. Medical management of acute and chronic low back pain. An evidence-based approach. Sydney (Australia): Elsevier; 2002.

13. Van de Laar FA, Kenealy T, Fahey $T$, et al. Elaboration of clinical prediction rules work. Available at: http://www.cochraneprimarycare.org/en/index.html/. Accessed January 10, 2010.

14. Ebell MH, Siwek J, Weiss BD, et al. Strength of recommendation taxonomy (SORT): a patient-centered approach to grading evidence in the medical literature. Am Fam Physician 2004;69(3):548-56.

15. McCormick A, Fleming DM, Charlton J. Morbidity statistics from general practice: fourth national study 1991-1992. Available at: http://www.statistics.gov.uk/ downloads/theme_health/MB5No3.pdf. Accessed February 14, 2010.

16. Nilsson S, Scheike M, Engblom D, et al. Chest pain and ischaemic heart disease in primary care. Br J Gen Pract 2003;53(490):378-82.

17. Verdon F, Burnand B, Herzig $L$, et al. Chest wall syndrome among primary care patients: a cohort study. BMC Fam Pract 2007;8:51.

18. Ruigomez A, Rodriguez LA, Wallander MA, et al. Chest pain in general practice: incidence, comorbidity and mortality. Fam Pract 2006;23(2):167-74.

19. Klinkman MS, Stevens D, Gorenflo DW. Episodes of care for chest pain: a preliminary report from MIRNET. J Fam Pract 1994;38:345-52.

20. Gibbons RJ, Balady GJ, Bricker JT, et al. ACC/AHA 2002 guideline update for exercise testing: summary article: a report of the American College of Cardiology/American Heart Association Task Force on Practice Guidelines (Committee to Update the 1997 Exercise Testing Guidelines). Circulation 2002;106:1883-92.

21. Berger JP, Buclin R, Haller E, et al. Right arm involvement and pain extension can help to differentiate coronary diseases from chest pain of other origin: a prospective emergency ward study of 278 consecutive patients admitted for chest pain. J Intern Med 1990;227:165-72.

22. Goodacre S, Locker T, Morris F, et al. How useful are clinical features in the diagnosis of acute, undifferentiated chest pain? Acad Emerg Med 2002;9(3):203-8.

23. Bruyninckx R, Aertgeerts B, Bruyninckx $P$, et al. Signs and symptoms in diagnosing acute myocardial infarction and acute coronary syndrome: a diagnostic meta-analysis. Br J Gen Pract 2008;58(547):105-11.

24. Panju AA, Hemmelgarn BR, Guyatt GH, et al. The rational clinical examination. Is this patient having a myocardial infarction? JAMA 1998;280(14):1256-63. 
25. Miller CD, Lindsell CJ, Khandelwal S, et al. Is the initial diagnostic impression of "noncardiac chest pain" adequate to exclude cardiac disease? Ann Emerg Med 2004;44(6):565-74.

26. McCord J, Nowak RM, Hudson MP, et al. The prognostic significance of serial myoglobin, troponin I, and creatine kinase-MB measurements in patients evaluated in the emergency department for acute coronary syndrome. Ann Emerg Med 2003;42(3):343-50.

27. National Heart Foundation of Australia, Cardiac Society of Australia and New Zealand. Guidelines for the management of acute coronary syndromes 2006. Med J Aust 2006;184(8):S1-30.

28. Law K, Elley R, Tietjens J, et al. Troponin testing for chest pain in primary healthcare: a survey of its use by general practitioners in New Zealand. N Z Med J 2006;119(1238):U2082.

29. Hamm CW, Goldmann BU, Heeschen C, et al. Emergency room triage of patients with acute chest pain by means of rapid testing for cardiac troponin Tor troponin I. N Engl J Med 1997;337(23):1648-53.

30. Ebell MH, Flewelling D, Flynn CA. A systematic review of troponin T and I for diagnosing acute myocardial infarction. J Fam Pract 2000;49:550-6.

31. Ebell MH, White LL, Weismantel D. A systematic review of troponin T and I values as a prognostic tool for patients with chest pain. J Fam Pract 2000;49:746-53.

32. Diercks DB, Boghos E, Guzman H, et al. Changes in the numeric descriptive scale for pain after sublingual nitroglycerin do not predict cardiac etiology of chest pain. Ann Emerg Med 2005;45(6):581-5.

33. Henrikson CA, Howell EE, Bush DE, et al. Chest pain relief by nitroglycerin does not predict active coronary artery disease. Ann Intern Med 2003;139(12):979-86.

34. Steele R, McNaughton T, McConahy M, et al. Chest pain in emergency department patients: if the pain is relieved by nitroglycerin, is it more likely to be cardiac chest pain? CJEM 2006;8(3):164-9.

35. Shry EA, Dacus J, Van De Graaff E, et al. Usefulness of the response to sublingual nitroglycerin as a predictor of ischemic chest pain in the emergency department. Am J Cardiol 2002;90(11):1264-6.

36. Wells PS, Anderson DR, Rodger M, et al. Excluding pulmonary embolism at the bedside without diagnostic imaging: management of patients with suspected pulmonary embolism presenting to the emergency department by using a simple clinical model and d-dimer. Ann Intern Med 2001;135(2):98-107.

37. Chunilal SD, Eikelboom JW, Attia J, et al. Does this patient have pulmonary embolism? JAMA 2003;290:2849-58.

38. Tamariz LJ, Eng J, Segal JB, et al. Usefulness of clinical prediction rules for the diagnosis of venous thromboembolism: a systematic review. Am J Med 2004;117(9):676-84.

39. Yap KS, Kalff $\mathrm{V}$, Turlakow A, et al. A prospective reassessment of the utility of the Wells score in identifying pulmonary embolism. Med J Aust 2007;187(6):333-6.

40. Stein PD, Hull RD, Patel KC, et al. D-dimer for the exclusion of acute venous thrombosis and pulmonary embolism: a systematic review. Ann Intern Med 2004;140(8):589-602.

41. Musset D, Parent F, Meyer G, et al. Diagnostic strategy for patients with suspected pulmonary embolism: a prospective multicentre outcome study. Lancet 2002;360:1914-20.

42. Perrier A, Roy PM, Aujesky D, et al. Diagnosing pulmonary embolism in outpatients with clinical assessment, D-dimer measurement, venous ultrasound, and helical computed tomography: a multicenter management study. Am J Med 2004;116(5):291-9. 
43. Qaseem A, Snow V, Barry P, et al. Joint American Academy of Family Physicians/ American College of Physicians panel on deep venous thrombosis/pulmonary embolism. Current diagnosis of venous thromboembolism in primary care: a clinical practice guideline from the American Academy of Family Physicians and the American College of Physicians. Ann Fam Med 2007;5(1):57-62.

44. van Belle A, Büller HR, Huisman MV, et al. Christopher Study Investigators. Effectiveness of managing suspected pulmonary embolism using an algorithm combining clinical probability, D-dimer testing, and computed tomography. JAMA 2006;295(2):172-9.

45. Institute for Clinical Systems Improvement. Healthcare guidelines. Venous thromboembolism. Diagnosis and treatment (guideline). Available at: http://www.icsi. org/guidelines_and_more/gl_os_prot/cardiovascular/venous_thromboembolism/ venous_thromboembolism_6.html. Accessed January 15, 2010.

46. Davie AP, Caruana FL, Sutherland GR, et al. Assessing diagnosis in heart failure: which features are any use? QJM 1997;90:335-9.

47. Talreja D, Gruver C, Sklenar J, et al. Efficient utilization of echocardiography for the assessment of left ventricular systolic function. Am Heart J 2000;139:394-8.

48. Cardarelli R, Lumicao TG. B-Type natriuretic peptide: a review of its diagnostic, prognostic, and therapeutic monitoring value in heart failure for primary care physicians. J Am Board Fam Pract 2003;16:327-33.

49. Maisel AS, Krishnaswamy P, Nowak RM, et al. Rapid measurement of B-type natriuretic peptide in the emergency diagnosis of heart failure. $\mathrm{N}$ Engl $\mathrm{J}$ Med 2002;347(3):161-7.

50. Dickstein K, Cohen-Solal A, Filippatos G, et al. ESC Guidelines for the diagnosis and treatment of acute and chronic heart failure 2008: the Task Force for the Diagnosis and Treatment of Acute and Chronic Heart Failure 2008 of the European Society of Cardiology. Eur Heart J 2008;29(19):2388-442.

51. Hunt SA, Abraham WT, Chin MH, et al. 2009 focused update incorporated into the ACC/AHA 2005 guidelines for the diagnosis and management of heart failure in adults: a report of the American College of Cardiology Foundation/American Heart Association Task Force on Practice Guidelines: developed in collaboration with the International Society for Heart and Lung Transplantation. Circulation 2009;119(14):e391-479.

52. Wiesenfarth J. Dissection, aortic. eMedicine. Available at: http://emedicine. medscape.com/article/756835-overview. Accessed January 15, 2010.

53. Spittell PC, Spittell JA Jr, Joyce JW, et al. Clinical features and differential diagnosis of aortic dissection: experience with 236 cases (1980 through 1990). Mayo Clin Proc 1993;68(7):642-51.

54. Woodhead M, Blasi F, Ewig S, et al. Guidelines for the management of adult lower respiratory tract infections. Eur Respir J 2005;26(6):1138-80.

55. Metlay JP, Kapoor WN, Fine MJ. Does this patient have community-acquired pneumonia? Diagnosing pneumonia by history and physical examination. JAMA 1997;278:1440-5.

56. Woodhead MA, Macfarlane JT, McCracken JS, et al. Prospective study of the aetiology and outcome of pneumonia in the community. Lancet 1987;1:671-4.

57. Diehr P, Wood RW, Bushyhead J, et al. Prediction of pneumonia in outpatients with acute cough - a statistical approach. J Chronic Dis 1984;37:215-25.

58. Smith SM, Fahey T, Smucny J, et al. Antibiotics for acute bronchitis. Cochrane Database Syst Rev 2004;(4):CD000245. DOI:10.1002/14651858.CD000245.pub2.

59. Hopwood P, Stephens RJ. Symptoms at presentation for treatment in patients with lung cancer: implications for the evaluation of palliative treatment. The 
Medical Research Council (MRC) Lung Cancer Working Party. Br J Cancer 1995; 71(3):633-6.

60. Freedman ND, Leitzmann MF, Hollenbeck AR, et al. Cigarette smoking and subsequent risk of lung cancer in men and women: analysis of a prospective cohort study. Lancet Oncol 2008;9(7):649-56.

61. Peto R, Lopez AD, Boreham J, et al. Mortality from tobacco in developed countries: indirect estimation from national vital statistics. Lancet 1992;339(8804): 1268-78.

62. Schreiber G, McCrory DC. Performance characteristics of different modalities for diagnosis of suspected lung cancer: summary of published evidence. Chest 2003;123(1 Suppl):115S-28S.

63. Butler KH, Swencki SA. Chest pain: a clinical assessment. Radiol Clin North Am 2006;44(2):165-79, vii.

64. Chang AK, Barton ED. Pneumothorax, iatrogenic, spontaneous and pneumomediastinum 2005. Available at: http://www.emedicine.com/EMERG/topic469.htm. Accessed January 15, 2010.

65. Yelland MJ. Back, chest and abdominal pain. How good are spinal signs at identifying musculoskeletal causes of back, chest or abdominal pain? Aust Fam Physician 2001;30(9):908-12.

66. Wise CM, Semble EL, Dalton CB. Musculoskeletal chest wall syndromes in patients with noncardiac chest pain: a study of 100 patients. Arch Phys Med Rehabil 1992;73(2):147-9.

67. Christensen HW, Vach W, Gichangi A, et al. Cervicothoracic angina identified by case history and palpation findings in patients with stable angina pectoris. J Manipulative Physiol Ther 2005;28(5):303-11.

68. Christensen HW, Vach W, Gichangi A, et al. Manual therapy for patients with stable angina pectoris: a nonrandomized open prospective trial. J Manipulative Physiol Ther 2005;28(9):654-61.

69. Stochkendahl MJ, Christensen HW, Vach W. Diagnosis and treatment of musculoskeletal chest pain: design of a multi-purpose trial. BMC Musculoskelet Disord 2008;9:40.

70. Fam AG, Smythe HA. Musculoskeletal chest wall pain. CMAJ 1985;133(5): 379-89.

71. Freeston J, Karim Z, Lindsay K, et al. Can early diagnosis and management of costochondritis reduce acute chest pain admissions? J Rheumatol 2004; 31(11):2269-71.

72. Proulx AM, Zryd TW. Costochondritis: diagnosis and treatment. Am Fam Physician 2009;80(6):617-20.

73. De Maeseneer M, De Mey J, Debaere C, et al. Rib fractures induced by coughing: an unusual cause of acute chest pain. Am J Emerg Med 2000;18(2):194-7.

74. Kara M, Dikmen E, Erdal HH, et al. Disclosure of unnoticed rib fractures with the use of ultrasonography in minor blunt chest trauma. Eur $\mathrm{J}$ Cardiothorac Surg 2003;24(4):608-13.

75. Wolfe F, Smythe HA, Yunus MB, et al. The American College of Rheumatology 1990 criteria for the classification of fibromyalgia. Report of the Multicenter Criteria Committee. Arthritis Rheum 1990;33(2):160-72.

76. Faybush EM, Fass R. Diagnosis of noncardiac chest pain. In: Fass R, Eslick GD, editors. Noncardiac chest pain: a growing medical problem. San Diego (CA): Plural Publishing; 2007.

77. Alban-Davies H, Jones DB, Rhoades J. Esophageal angina as the cause of chest pain. JAMA 1982;248:227. 
78. Eslick GD, Coulshed DS, Talley NJ. Diagnosis and treatment of noncardiac chest pain. Nat Clin Pract Gastroenterol Hepatol 2005;2(10):463-72.

79. Klauser AG, Schindlbeck NE, Muller-Lissner SA. Symptoms in gastro-oesophageal reflux disease. Lancet 1990;335(8683):205-8.

80. Fang J, Bjorkman D. A critical approach to noncardiac chest pain: pathophysiology, diagnosis, and treatment. Am J Gastroenterol 2001;96(4):958-68.

81. Ofman JJ, Gralnek IM, Udani J, et al. The cost-effectiveness of the omeprazole test in patients with noncardiac chest pain. Am J Med 1999;107(3):219-27.

82. MacArthur $C$, Smith $A$. The symptom presentation of breast cancer: is pain a symptom? Community Med 1983;5(3):220-3.

83. Greenblatt RB, Samaras C, Vasquez JM, et al. Fibrocystic disease of the breast. Clin Obstet Gynecol 1982;25(2):365.

84. Goh CL, Khoo L. A retrospective study of the clinical presentation and outcome of herpes zoster in a tertiary dermatology outpatient referral clinic. Int J Dermatol 1997;36(9):667-72.

85. Li Q, Chen N, Yang J, et al. Antiviral treatment for preventing postherpetic neuralgia. Cochrane Database Syst Rev 2009;(2):CD006866. DOI:10.1002/ 14651858.CD006866. pub2.

86. Bass C, Wade C, Hand D, et al. Patients with angina with normal and near normal coronary arteries: clinical and psychosocial state 12 months after angiography. Br Med J (Clin Res Ed) 1983;287(6404):1505-8.

87. Strike PC, Steptoe A. Systematic review of mental stress-induced myocardial ischaemia. Eur Heart J 2003;24(8):690-703.

88. Katerndahl DA, Trammell C. Prevalence and recognition of panic state in STARNET patients presenting with chest pain. J Fam Pract 1997;45:54-63.

89. Arroll B, Khin N, Kerse N. Screening for depression in primary care with two verbally asked questions: cross sectional study. BMJ 2003;327(7424):1144-6.

90. Kisely S, Campbell LA, Skerritt P. Psychological interventions for symptomatic management of non-specific chest pain in patients with normal coronary anatomy. Cochrane Database Syst Rev 2005;(1):CD004101.

91. Furukawa TA, Watanabe N, Churchill R. Combined psychotherapy plus antidepressants for panic disorder with or without agoraphobia. Cochrane Database Syst Rev 2007;(1):CD004364. DOI:10.1002/14651858.CD004364.pub2.

92. Arroll B, Elley CR, Fishman T, et al. Antidepressants versus placebo for depression in primary care. Cochrane Database Syst Rev 2009;(3):CD007954. DOI:10.1002/14651858.

93. Peretti S, Judge R, Hindmarch I. Safety and tolerability considerations: tricyclic antidepressants vs. selective serotonin reuptake inhibitors. Acta Psychiatr Scand 2000;403:17.

94. Komaroff AL. Algorithms and the 'Art' of medicine. Aust J Polit Hist 1982;72(1): 10-2.

95. Fam AG. Approach to musculoskeletal chest wall pain. Prim Care 1988;15(4): 767-82.

96. Mousavi S, Tosi J, Eskandarian R, et al. Role of clinical presentation in diagnosing reflux-related non-cardiac chest pain. J Gastroenterol Hepatol 2007;22(2): 218-21. 